\title{
EN ISO 52016-1: The New International Standard To Calculate Building Energy Needs for Heating And Cooling, Internal Temperatures And Heating And Cooling Load
}

\author{
Dick van Dijk ${ }^{1}$ \\ ${ }^{1}$ EPB-research - Dick van Dijk, Delft, The Netherlands
}

\begin{abstract}
The set of Energy Performance of Buildings (EPB) standards has been published in 2017. One of the key EPB standards is (EN) ISO 52016-1, to calculate the energy needs for heating and cooling, internal temperatures and sensible and latent heat loads. This standard replaces (EN) ISO 13790:2008. Like its predecessor, ISO 52016-1 contains both a monthly and hourly method, but the hourly method in ISO 52016-1 is more advanced and better suited to deal with dynamic effects. Additional standardization work has been initiated to further increase the applicability: (1) to include the effect of adaptive façade elements and (2) to introduce specific criteria and validation procedures for alternative calculation procedures.
\end{abstract}

\section{Introduction}

The set of Energy Performance of Buildings (EPB) standards has been published in summer 2017. This set enables to assess the overall energy performance of a building. A number of key EPB standards are available at global level (the (EN) ISO 52000 family of standards), while others are for this moment only available at European level (CEN standard: EN xxxx).

(EN) ISO 52016-1 (International Organization for Standardization, 2017), accompanied by the technical report (CEN) ISO/TR ISO 52016-2 (International Organization for Standardization, 2017) ${ }^{1}$, is one of the key standards of the ISO 52000 family. ISO 52016-1 provides the method to calculate the energy needs for heating and cooling, internal temperatures and sensible and latent heat loads. It replaces the renowned and widely used ISO 13790 (International Organization for Standardization, 2008). Like its predecessor, ISO 520161 contains both a monthly and hourly method. The hourly method in ISO 52016-1 is more advanced than the simplified hourly method in ISO 13790 and better suited to deal with dynamic interactions between building components and system elements. At the same time, it has been tailored in such a way that it remains fully transparent and requires no extra input data compared to the monthly method.

\footnotetext{
${ }^{1}$ From here on, the addition "EN" and "CEN" will be omitted when referring to EN ISO standards or CEN ISO technical reports.
}

This paper focusses mainly on the rationale behind and the wide applicability of the hourly calculation method of ISO 52016-1 and how this relates to dynamic building simulation tools.

\section{The set of EPB standards}

The set of standards and accompanying technical reports on the energy performance of buildings (set of EPB standards) have been prepared $(2011$ - 2016) under a mandate, given to CEN by the European Commission and the European Free Trade Association, to support the EPBD (Mandate M/480, 2010).

Figure 1 shows a simplified flow chart of the main modules or elements in the assessment of the energy performance of buildings. Each of these modules is covered by one or more EPB standards.

A complete overview of all EPB standards is given at the EPB Center website (www.epb.center, EPB Center, 2019). More background information can also be found in recent articles, e.g. in the REHVA Journal (Hogeling, 2016a and 2016b, 2017 and van Dijk and Hogeling, 2019).

\section{Holistic approach: instrument for policy targets and driver for innovation}

In the past, energy performance requirements were set at component level - minimum thermal insulation levels and minimum efficiencies of products. However, nowadays this would lead to sub-optimal solutions and create a barrier to the necessary technology transitions.

The set of EPB standards is based on the holistic or systemic approach: the assessment of the overall energy performance of a building. This implies that all types of building related energy uses (heating, lighting, cooling, air conditioning, ventilation) and outdoor climatic and local conditions, as well as indoor climate requirements are considered, including the sometimes complex and dynamic interactions between these various aspects.

This also implies that any combination of technologies can be used to reach the intended overall energy performance level, at the lowest cost. Due to this 'competition' between different technologies, the holistic approach is a key driver for technological innovation and change.

Of course, to benefit optimally from the holistic approach the EPB standards have to be able to cope adequately with innovative techniques. In this respect, 
the main distinction is between hourly and monthly calculation time intervals. This is explained in more detail further on.

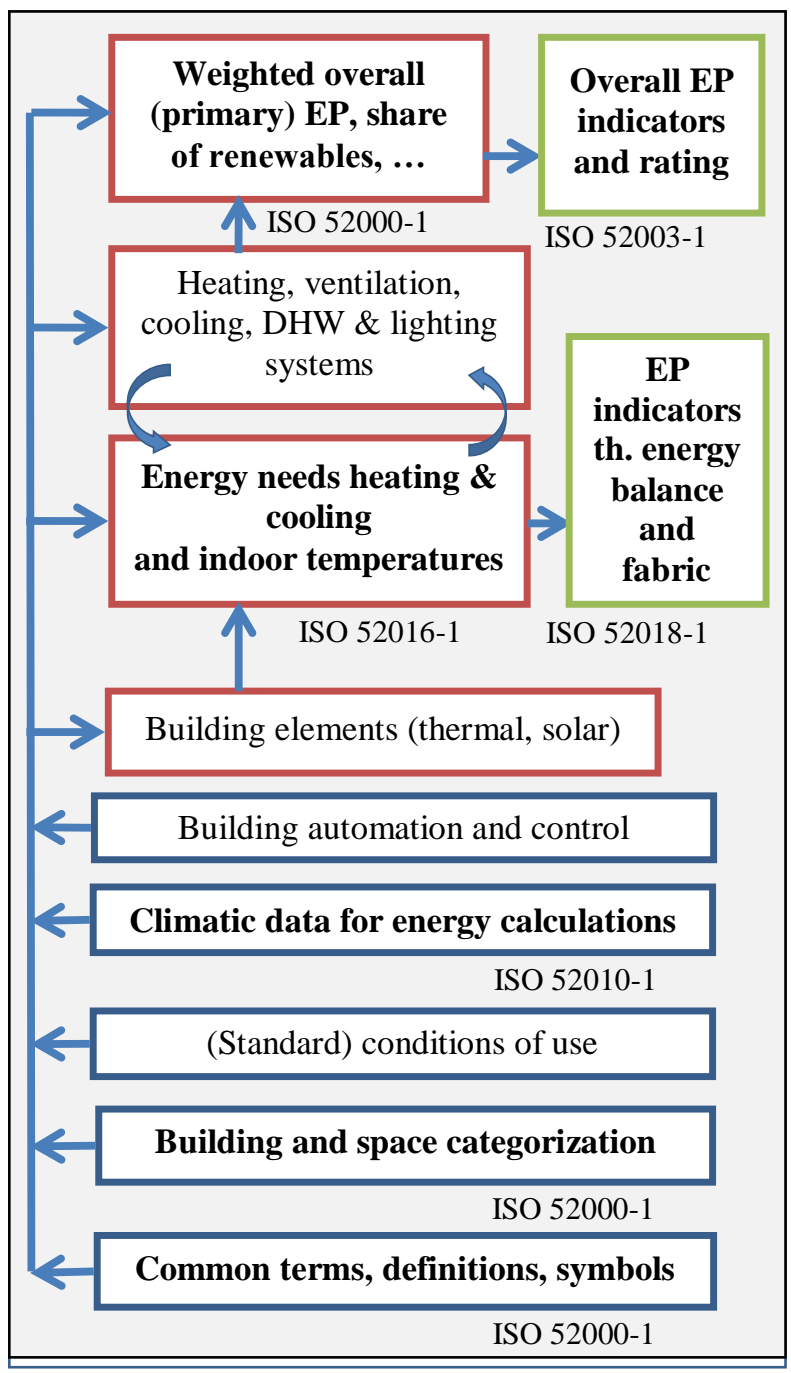

Figure 1: Flow chart of the set of EPB standards with position of the five key EPB standards (in bold).

\section{The five key standards mentioned in EPBD}

The revised European Energy Performance of Buildings Directive (EPBD, 2018), mentions explicitly five key (in EPBD called: 'overarching') standards of the EPB set: ISO 52000-1, 52003-1, 52010-1, 52016-1 and 52018-1. The EU member states are obliged to take these standards into account in their reports to the European Commission.

Figure 1 (roughly) shows which elements are covered by these standards (bold and numbered). These five key EPB standards have in common that each of them describes an important step in the assessment of the energy performance of building. It is very fortunate that these five EPB standards are also available as ISO standards, which creates a strong basis for the roll-out of the other (CEN) EPB standards at worldwide level as well. Harmonization of EPB assessment methodologies at global level will strengthen innovation on EPB solutions and products.
So ISO 52016-1 is one of these key EPB standards. In fact, the backbone of the holistic calculation is formed by ISO 52000-1 and ISO 52016-1, with input from the product-related standards and in interaction with the system standards.

\section{Hourly and monthly calculation procedures The overarching EPB standard ISO 52000-1}

The overarching EPB standard ISO 52000-1 (International Organization for Standardization, 2017) lists different options for the time interval for the calculation of the energy performance: hourly, monthly, seasonal, yearly and bin. The choice can be made at national level. In most countries a choice is made between monthly and hourly calculation procedures.

\section{Balanced accuracy}

For use in the context of building regulations it is essential that the procedures to calculate the energy performance of a building are not only accurate, but also robust (applicable to a wide range of cases). It is also essential that they are reproducible (unambiguous) as well as transparent and verifiable (e.g. for municipalities, to check compliance with national or regional minimum energy performance requirements) and applicable/affordable (e.g. for inspectors, assessing the energy performance assessment of an existing building).

The accuracy of the model should always be in proportion with the limitations and uncertainties in available input data and with the required robustness and reproducibility of the method. But at the same time the calculation should provide a sufficient and realistic appreciation of the wide variety of available energy saving technologies: a balanced accuracy.

The importance of keeping a balance between accuracy and quality of input was introduced more than a decade ago by Bart Poel (e.g.: Poel, 2007). He proved that, for a specific application, the most accurate, complete and state of the art method is not necessarily the most appropriate method. This is in particular true for calculations in the context of building regulations, and is very strongly true for existing buildings.

\section{Low energy use: strong dynamic effects}

Still keeping a balanced accuracy in mind, many technologies, in particular for low energy buildings aiming to meet today's energy performance requirements, are strongly and dynamically interacting with the hourly and daily variations in weather and operation (solar blinds, thermostats, needs, occupation, accumulation, mechanical ventilation, night time -free cooling- ventilation, weekend operation, heat pump, solar panels, etc.). This has a strong effect on the calculated energy performance.

In the past, the dynamic effects had less prominent effects, but in low energy buildings these effects can become very large (van Dijk, 2018). This strongly influences the pro's and con's of the monthly versus hourly calculation method. 


\section{Monthly vs hourly method in ISO 52016-1 ISO 52016-1:2017: successor of ISO 13790:2008}

Of all EPB standards, the choice between hourly or monthly calculation procedures is most prominently visible in the calculation of the energy needs for heating and cooling and indoor temperatures: ISO 52016-1.

\section{Monthly method in ISO 52016-1}

The monthly calculation method in ISO 52016-1:2017 has not been fundamentally changed compared to it's predecessor ISO 13790:2008. It contains correction or correlation factors to account, in a kind of statistical way, for the dynamic effects that are mentioned above. These factors are usually pre-calculated, based on a large series of building simulations with e.g. variations of daily weather, conditions of use and building design.

However, for low energy buildings and buildings with dynamically (inter-)acting technologies, the monthly method is no longer the simple transparent method that it used to be. Due to the necessity to introduce an increasing number of correction factors, the original transparency and robustness of the monthly method has been lost. Moreover, a serious weakness of the monthly method is that the calculation of the monthly heating and cooling needs are done separately, without interaction.

\section{Hourly method in ISO 52016-1}

An hourly calculation method does not need the series of correction factors that the monthly method requires. It can directly calculate the effect of dynamic interactions. But the challenge for an hourly method is to avoid the need for too many input data from the user. As mentioned above ('Balanced accuracy'), more input data would introduce more uncertainties that could easily lead to a loss of overall accuracy, or lead to significantly higher EP assessment costs.

With this in mind, the hourly calculation method in ISO 52016-1 has been improved drastically compared to its predecessor (ISO 13790:2008), in two ways:

First: ISO 13790:2008 contained a very simple, aggregated (few lumped parameter nodes) model in which all building elements enclosing a thermal zone (except windows) were aggregated to a single overall thermal transmittance, including such different elements as roofs, walls and ground floor (see Figure 3). This is actually a loss of already available information (input data such as the $U$-value, size, orientation and mass of each building element) and leads -consequently- to problems in e.g. the estimation of the effects of thermal mass and the effects of solar irradiation. The only advantage of the lumped parameter model was the shorter calculation time, which -of course- is now less relevant than 10 years ago.

In contrast to this, ISO 52016-1 contains a full dynamic method, in which the $U$-value, size, orientation and mass of each building element are used directly, without aggregation (see Figure 3). Because each construction element is modelled separately, ISO 52016-1 is much more powerful and transparent than ISO 13790 and it resembles building simulation tools more closely. It also opens the possibility to deal with adaptive building elements.

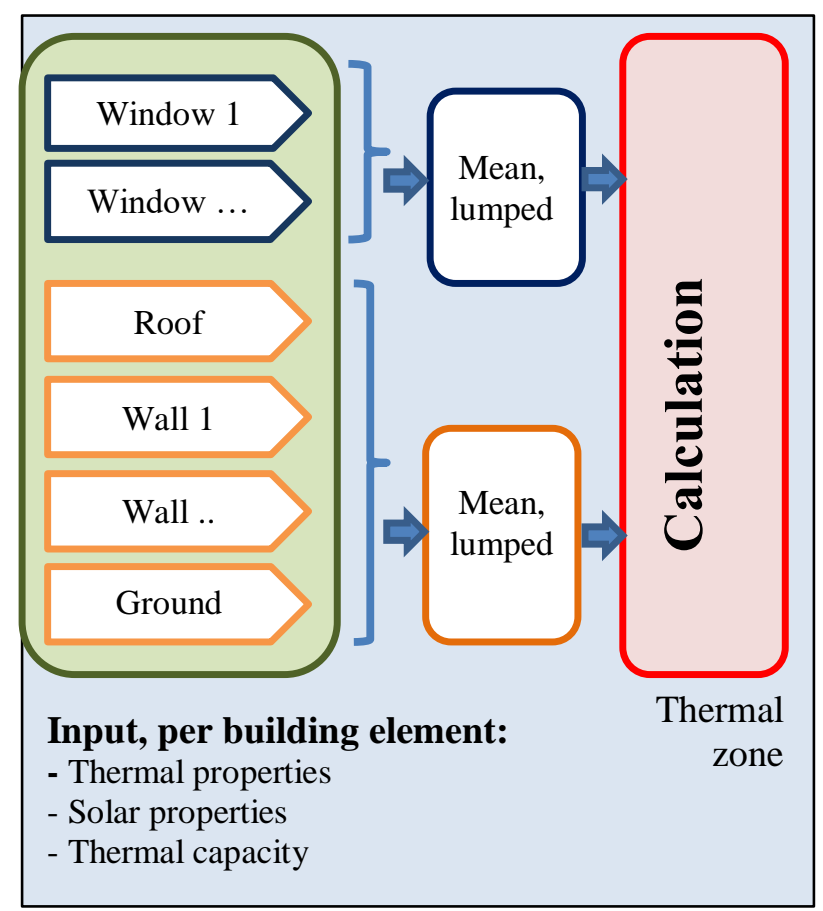

Figure 2. Illustration of simplified hourly method in ISO 13790:2008

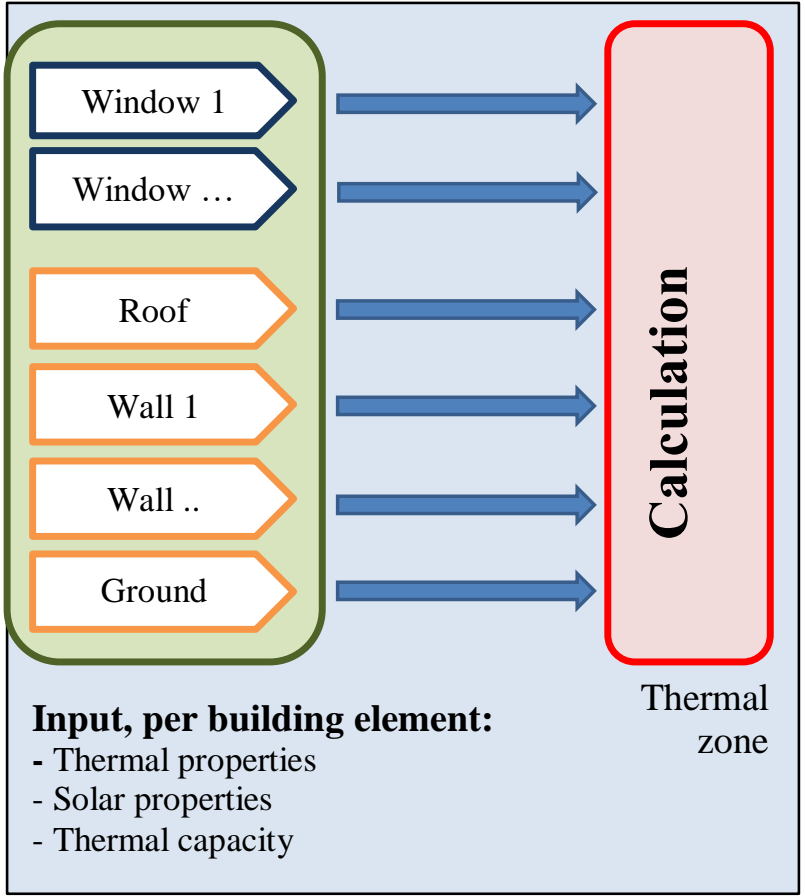

Figure 3. Illustration of improved hourly method in ISO 52016-1:2017

Of course, this is nothing different from conventional building simulation models (Loonen, 2017). The novelty is, that the details of this hourly method in ISO 52016-1 have been tailored to the goal: they are spelled out unambiguously and transparent and, equally important:

Second: One of the main accomplishments of this new hourly method is that it does not require extra input compared to the monthly calculation method. 


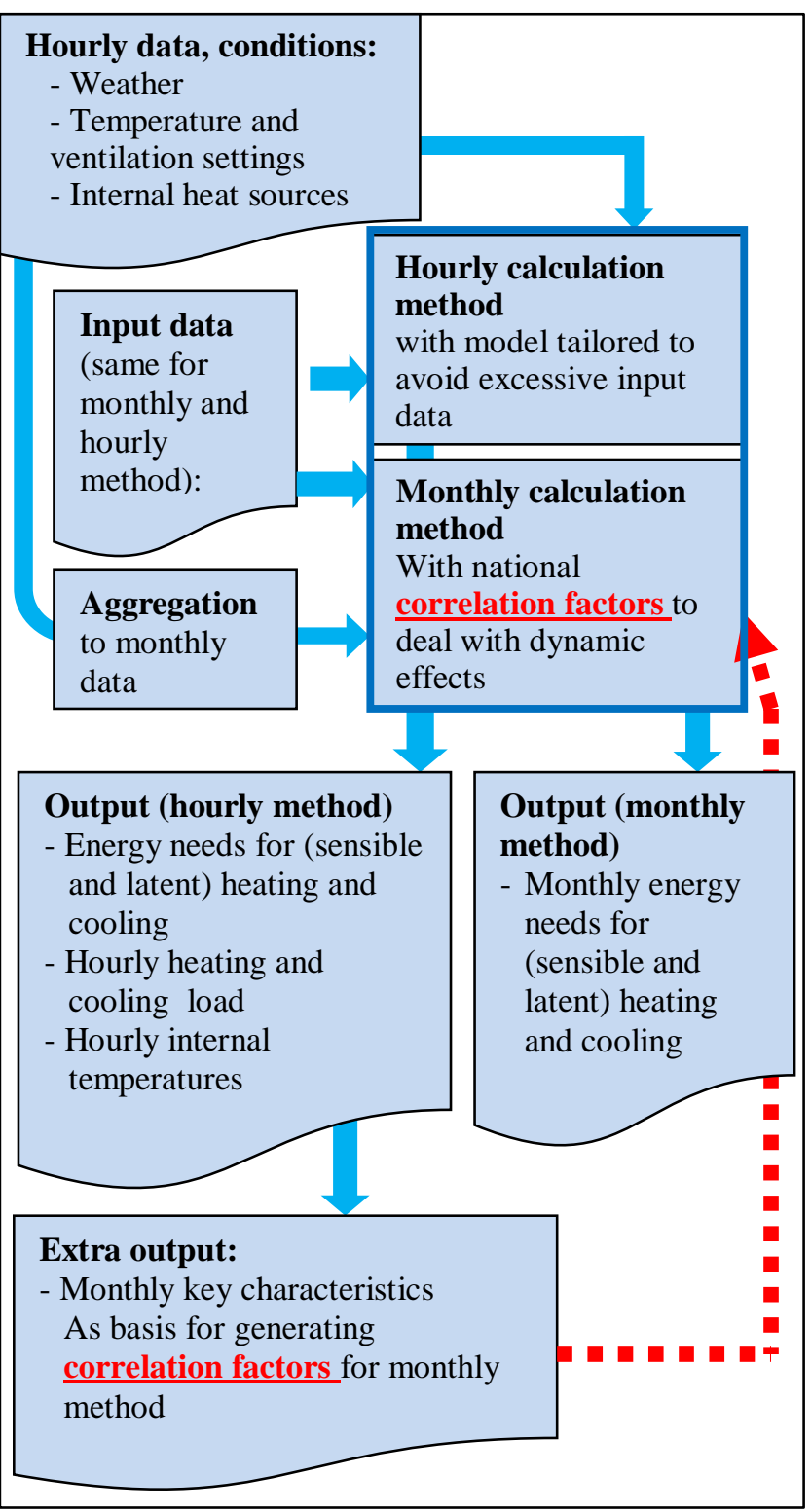

Figure 4. ISO 52016-1: links between the hourly and the monthly method provided in this standard

\section{Hourly method in ISO 52016-1 to derive monthly correlation factors}

The hourly and the monthly method in ISO 52016-1 are closely linked: they have been developed side by side and they use, all together, the same input data and assumptions. Consequently, the hourly method is also very well suited for the derivation or validation of the correction and correlation factors of the monthly method. For instance, by carrying out a large number of hourly calculation runs for a specific range of building categories, with a variety of building types and designs. This is illustrated by the flow chart in Figure 4.

Normally, another dynamic simulation tool is needed for such purpose; with the consequence that differences in assumed conditions and differences in model approaches lead to significant noise in the derivation/validation of the correction or correlation factors. By using the hourly and the monthly method both from ISO 52016-1 this noise is eliminated.
Link with ISO 52010-1 for the conversion of solar irradiation

One of the additional causes for the kind of "noise" mentioned above is the calculated solar irradiation at vertical and tilted planes, derived from the measured solar irradiation at horizontal plane. This is an important input for the calculation of energy needs and indoor temperatures, especially in case of low energy buildings.

The main internationally available building simulation tools use quite similar but yet different algorithms for this conversion. In the so called BESTEST cases (ANSI/ASHRAE, 2014) this is one of the causes for discrepancies between building simulation tools in the calculation cases on the energy needs for heating and cooling and indoor temperatures (see Table 1). With the introduction of ISO 52010-1 (International Organization for Standardization, 2017) this conversion of the solar irradiation to tilted and vertical planes has now been harmonized which eliminates this part of the noise. This is explained in more detail in 7.2.1 of ISO/TR 52016-2 (International Organization for Standardization, 2017).

\section{Why is "bin" not an option in ISO 52016-1?}

"Bin" refers to a statistical method, where, as step 1, for one or more boundary conditions, the frequency of occurrence of a specific value (within a given bandwidth) is counted over the year, using a specific short time interval (the "bins"). For example: the hourly values of the outdoor air temperature within a bandwidth of one or a few degrees. The result can be compared with a bar chart of the number of hours in a year with a given outdoor temperature.

As step 2, the calculation of the energy or thermal performance is done bin by bin, for each boundary condition. And finally, as step 3, the result is summed over all bins, each multiplied by the frequency of the respective bin.

This method is especially of value for calculations of technologies where the influence of the variation of a driving force is significant and -consequently- averaging is not acceptable (e.g. the outdoor temperature for air-towater heat pumps).

The limitation of the bin method is that there is no 'memory' between the bins. In case of energy storage systems or in case of heat accumulation in building elements, a bin does not know how much heat was accumulated or released during the previous time interval, because the bins are not sequential in time in contrast with the calculation using a sequence of (e.g. hourly) time intervals.

This limitation is the reason why a bin method is not an option for the calculation of the energy needs for heating and cooling in a building: the heat accumulation in the building mass typically stretches over several days.

\section{What about building simulation tools?}

For application in the context of building regulations (energy label, minimum energy performance requirements), a calculation method has to be realistic, 
sufficiently sensitive (=discriminating between technologies with different performance) and fair (level playing field). But also: affordable, reliable, verifiable and robust (to be trusted blindly for a wide variety of cases, reproducible and unambiguous).

A detailed dynamic simulation tool introduces many choices, details and complexities that go beyond what is needed to assess the energy performance of a building in the context of building regulations, thus requiring extra input data (including detailed boundary conditions) that are not available or -if available- not verifiable, maintainable or comparable (level playing field!).

\section{Initiative to open up ISO 52016-1}

Within ISO and CEN, initiatives are taken to explore the possibilities to open up the hourly calculation method of ISO 52016-1 by allowing, to a certain extent, alternative calculation methods, while maintaining unambiguity, transparency, robustness, verifiability, affordability and reproducibility and a level playing field for different products and technologies. The main challenge is to find a good balance between opening up the calculation procedures, while maintaining the existing quality aspects mentioned above. This requires, without reinventing the wheel (e.g. ANSI/ASHRAE, 2014), the specification of carefully designed or selected test cases with reference results and acceptance criteria.

\section{ISO 52016-1 versus ISO 52017-1}

ISO 52017-1 contains a generic (reference) hourly calculation method for (a thermal zone in) a building. It is called generic as it describes the physical process (energy balance) without specific assumptions, boundary conditions, simplifications or solution techniques.

ISO 52017-1 is based on and, together with ISO 520161, it replaces ISO 13791 and ISO 13792 (International Organization for Standardization, 2012). The main changes compared to ISO 13791 are:

(1) The energy needs for heating and cooling are added to the energy balance equations. This significantly increases the application range. is left up to the application standards like ISO 52016-1.

(2) The validation cases have been omitted. Validation requires specification of test cases, a variety of assumptions \& simplifications and input data and specification of the range of validity and accuracy. This makes more sense when the specific application is known. Ergo: to keep a clear distinction between the generic method and a specific application, verification and validation cases have been moved to ISO 52016-1.

ISO 52016-1 replaces ISO 13790:2008. The hourly calculation method in ISO 52016-1 is a specific application of the generic method provided in ISO 52017-1. ISO 52016-1 further contains specific boundary conditions, specific simplifications and input data, for each of the applications that are within its scope.

\section{Design heating and cooling load in ISO 52016-1}

ISO 52016-1 includes specific details and boundary conditions for the calculation of the design heating and cooling load, including latent heat load, as a basis for the dimensioning of equipment for cooling and dehumidification, on zone level or on central level. It specifies also the methods and conditions for the calculation of the humidification load. The main idea is that there is only one method needed for load and energy calculations for heating and cooling in case of an hourly calculation interval.

\section{System specific calculation of the energy needs for heating and cooling}

In addition to the calculation of the basic energy loads and needs, the effect of specific system properties can be taken into account in ISO 52016-1. This leads to systemspecific energy loads and needs. It concerns e.g.: (1) undersized heating or cooling power (hourly method only); (2) recoverable system heat losses (dissipated heat: effect on the energy balance); (3) adjustment of the temperature set-points (value and time-schedule) due to imperfect system control, and (4) limitation of the heating or cooling season for the calculation defined by the operation time of the respective technical systems.

And the other way around: in case of the hourly method, the hourly output of the calculation is important input for system standards, to assess the performance of the technical systems and their components as a function of the heating and cooling load and indoor environment temperature.

\section{Built in options to tailor the EPB standards to the national situation}

The set of EPB standards offers an internationally agreed set of methods to assess the energy performance of buildings in a harmonized, modular and transparent way. At the same time, the individual countries can tailor the standards to their national building regulations, building tradition, technology infrastructure and climate. They thus combine the benefits of an internationally harmonized approach with specific national or regional features. This is also the case for ISO 52016-1. More details can be found in van Dijk (2017) and van Dijk and Hogeling (2019).

\section{Validation of ISO 52016-1 against BESTEST cases}

The hourly calculation procedures on the thermal zone level have been validated by using relevant cases from the so called BESTEST series. The BESTEST cases are well established since decades (several IEA ECBCS annexes and IEA SHC tasks), widely used worldwide, well described (in particular in ANSI/ASHRAE, 2014) and regularly extended with additional cases.

The limitation of the BESTEST series is that there is no single reference "true" result and no acceptance criteria. The hourly calculation procedures in ISO 52016-1 are 
fully described ('prescribed'). This means that the results of the test cases should be the same for all users, if the same input data and boundary conditions are used. The test cases enable a verification of software tools based on this standard.

Of course, even without a reference ("true") result, it is interesting to compare the results with the results available from the renowned software tools. Some results are presented below.

The same BESTEST cases are also used for the validation of the procedures in ISO 52010-1, to calculate the distribution of solar radiation on a non-horizontal plane based on measured hourly solar radiation data on a horizontal surface. These results have been presented in Plokker and van Dijk (2016). The results of that calculation, the hourly irradiation at vertical planes of different orientation, are input for the validation tests of ISO 52016-1. The following cases were selected:

Table 1. The selected BESTEST cases

\begin{tabular}{|l|l|l|l|}
\hline $\begin{array}{l}\text { Case } \\
\text { identifier }\end{array}$ & $\begin{array}{l}\text { Continuous } \\
\text { heating and } \\
\text { cooling }\end{array}$ & $\begin{array}{l}\text { Intermittent } \\
\text { heating and } \\
\text { cooling }\end{array}$ & $\begin{array}{l}\text { No heating } \\
\text { and cooling } \\
\text { (free float) }\end{array}$ \\
\hline $\begin{array}{l}\text { Lightweight } \\
\text { construction }\end{array}$ & 600 & 640 & $600 \mathrm{FF}$ \\
\hline $\begin{array}{l}\text { Heavyweight } \\
\text { construction }\end{array}$ & 900 & 940 & $900 \mathrm{FF}$ \\
\hline
\end{tabular}

Note that the selected BESTEST test cases do not include for instance:

- Ground floor heat transfer coupled to ground.

- Thermal coupling between two or more zones.

- The effect of thermal bridges.

- Sunspace or other thermally unconditioned spaces.

- Solar shading by external obstacles (distant, remote or from own building elements).

- Complex control patterns (e.g. weekend interruption of mechanical ventilation and/or heating and cooling and/or solar shading, etc.; night time ventilation as free cooling, heat recovery by pass, ...)

The ground floor heat transfer has been validated separately, as described in ISO/TR 52019-2 (International Organization for Standardization, 2017).

In the selected BESTEST cases the heat transfer is decoupled from the ground. The other features may be tested analytically or require dynamic links with system related calculation standards.

The composite Figure 5 provides the main results of the Case 600 and 600FF. Note that the climate is Denver (Col., USA), with quite cold but sunny winter and warm and sunny summer.

It also has to be taken into consideration that not each software program who's results are available for the comparison use nowadays state-of-the-art algorithms (in that sense these are not reference results). This is because these base cases of the BESTEST series were created and tested many years ago.
The technical report ISO/TR ISO 52016-2 provides background information, explanation (including examples) and justification (including more validation cases). For example: comparison of peak hourly heating load against the "reference" programs for Case 940 (heavy weight, night set back) is the only result that shows a significant discrepancy: ISO $520161,8 \mathrm{~kW}$, with the reference programs between $4,0 \mathrm{~kW}$ and 6,4 $\mathrm{kW}$. Note that in ISO 520161 the operative temperature is used for the set-point. This requires much more power than only heating the air. Heating up only the air temperature to the set point and disregarding a low mean radiative temperature does not lead to the thermal comfort that is expected by the occupants and expected as standard conditions for the calculation of the system design capacity. The peak hourly cooling load does not show a significant discrepancy, so it is especially for the fast heating up after night set back (in the given cold climate!) that this phenomenon occurs.
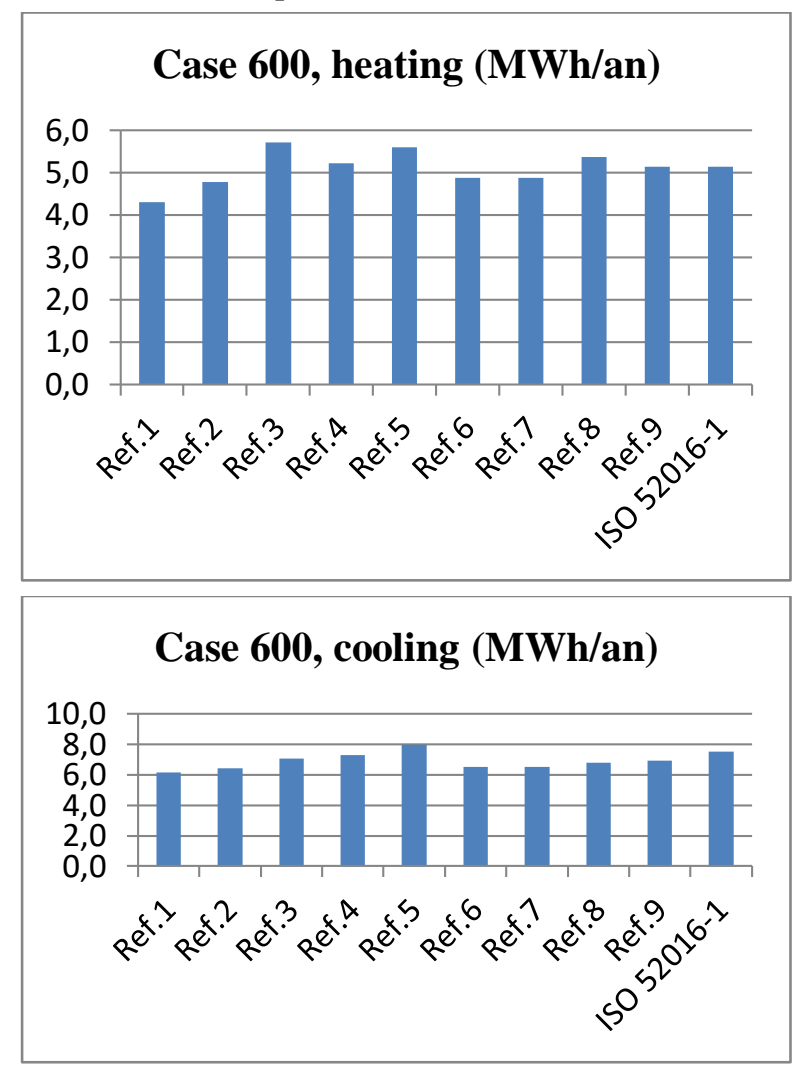

Case 600, peak heating load (kW)

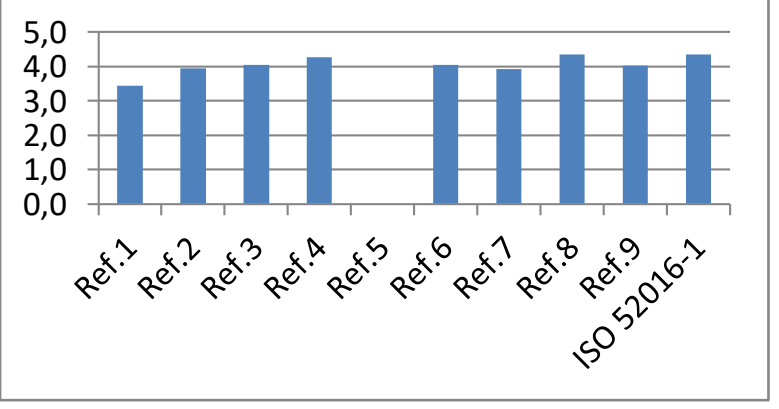




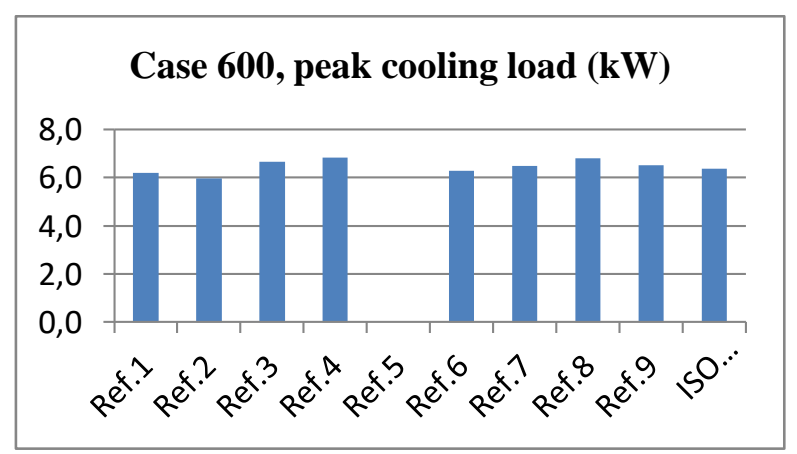

Case 600FF, min.indoor temp. $\left({ }^{\circ} \mathrm{C}\right)$

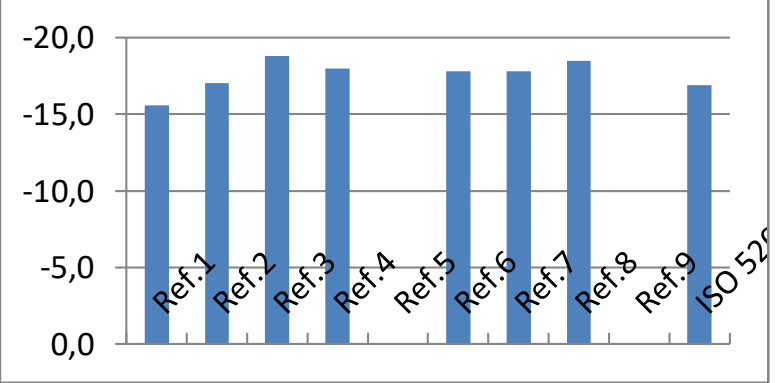

Case 600FF, max.indoor temp. $\left({ }^{\circ} \mathbf{C}\right)$
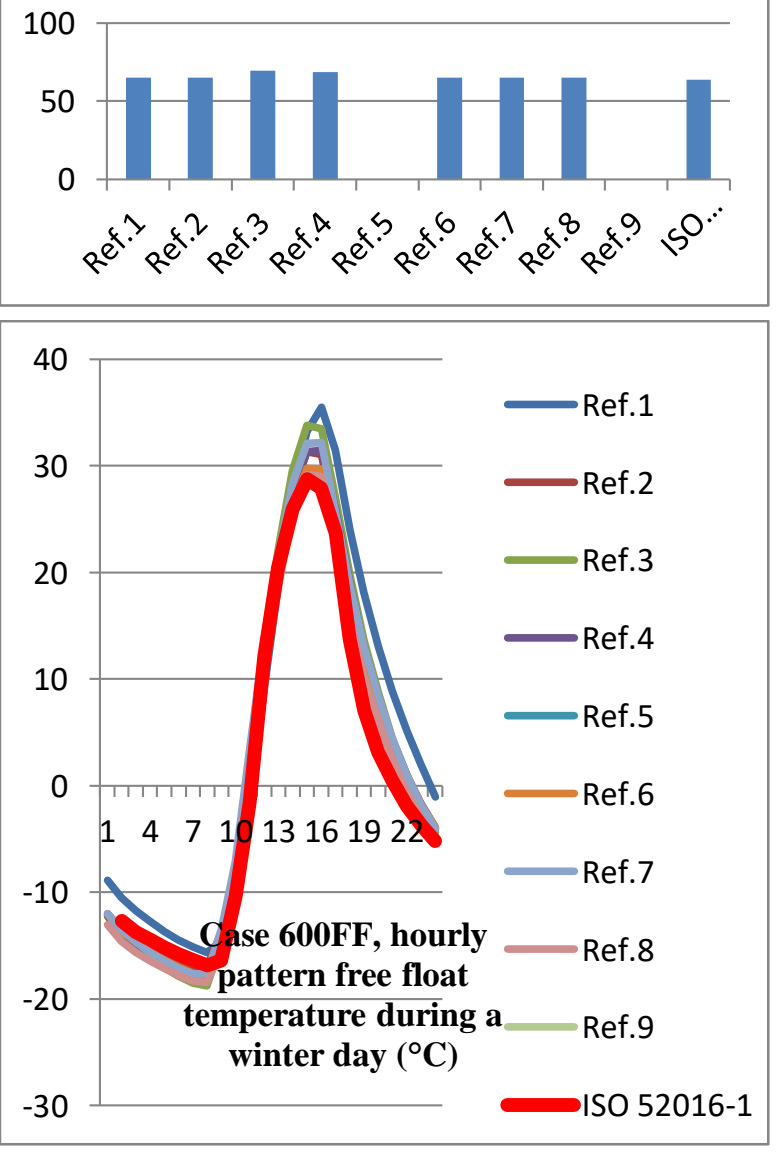

Figure 5. BESTESTS: Main results for Case 600 and 600FF, ISO 52016-1 compared with the available 9 reference tools

\section{Accompanying spreadsheet}

A detailed spreadsheet was produced on ISO 52016-1 in parallel with the standard, to test and demonstrate both the hourly and the monthly calculation method. With this spreadsheet the hourly and monthly method can be compared directly in the same run. This spreadsheet was also used for the validation cases shown above. A draft of the spreadsheet is publicly available since May 2015, based on the draft standard (www.EPB.center). An update will become available around May 2019.

\section{Adaptive facade elements}

As shown by Loonen (2017), performance prediction of adaptive facades can be a challenging task and the information on this topic is scarce and fragmented.

A new (EN) ISO standard is in preparation (2018-2020) that builds on ISO 52016-1, but adds the extra elements in the calculation that are needed in case adaptive building envelope elements are involved. The advantage of using ISO 52016-1 is that it is fully dynamic but relatively simple and fully transparent.

This facilitates linking the thermo-physical model of the adaptive façade elements to the hourly model of ISO 52016-1. This also makes the translation straightforward, from the physical control parameters (climate boundary conditions, material or zone states, occupant preference or even HVAC, BMS interaction) to the parameters in the ISO 52016-1 model.

On the other hand, because lighting and ventilation are covered in separate EPB standards, it will cost extra efforts to ensure that these aspects are correctly integrated in the calculations.

However, the main challenge will be to reach agreement on specific default control strategies. Without common assumptions on the control strategy there is no level playing field for the comparison of the predicted energy performance of products. For this new standard it is envisaged, starting with the most representative categories of adaptive façade technologies, to develop specific default control strategies at 3 or 4 successive levels of complexity.

\section{Conclusion}

The set of EPB standards has been published in 2017. One of the key EPB standards is (EN) ISO 52016-1, the successor of ISO 13790:2008. This paper focussed mainly on the rationale behind and the wide applicability of the hourly calculation method of ISO 52016-1 and how this relates to dynamic building simulation tools.

ISO 52016-1 offers the robustness, transparency and reproducibility that is required for EPB calculations in the context of building regulations.

The hourly method in ISO 52016-1 paved the ground for additional standardization work: (1) to add extra elements in the calculation that are needed in case adaptive building envelope elements are involved and (2) to set up specific validation cases that enable alternative methods for specific calculation elements in 
ISO 52016-1. These new developments will further increase the applicability of the set of EPB standards.

\section{References}

ANSI/ASHRAE (2014), Standard Method of Test for the Evaluation of Building Energy Analysis Computer Programs (ANSI/ASHRAE 140).

Dijk, D. van (2017), The set of EPB standards: spotlight on the EN ISO 52000 family, REHVA Journal, 54 (6), 31 - 36 .

Dijk, D. van (2018), EPB standards: Why choose hourly calculation procedures?, REHVA Jrnl, 55 (1), 6-12.

Dijk, D. van and J. Hogeling (2019), The new EN ISO 52000 family of standards to assess the energy performance of buildings put in practice?, Clima2019 Conference Proceedings (in preparation).

EPB Center (2019), The information and communication platform on the set of EPB standards, www.epb.center.

EPBD (2018), Directive (EU) 2018/844 of 30 May 2018 amending Directive 2010/31/EU on the energy performance of buildings and Directive 2012/27/EU on energy efficiency.

Hogeling, J. (ed.) (2016a), REHVA Journal Special issue “EPB standards”, 53 (3), 5 - 48.

Hogeling, J. (2016), Special issue EPB standards published for formal vote, REHVA Jl, 53 (6), 7 - 47.

Hogeling, J. (2017), The implementation of the new EPB-standards will boost product and HVAC system innovation and create new market opportunities for the HVAC industry, REHVA Journal, 54 (1), 4.

Hogeling, J. (2018), Service Contract $\mathrm{N}^{\mathrm{O}}$ ENER/C3/2017-437/ SI2.785185 with the Europ.Comm., DG Energy (Sept. 2018 - Sept. 2021), Support the Dissemination and Roll-out of the Set of Energy Performance of Building Standards developed under EC Mandate M/480.

International Organization for Standardization (2008). Energy performance of buildings - Calculation of energy use for space heating and cooling ([EN] ISO 13790). Superseded by [EN] ISO 52016-1.

International Organization for Standardization (2012). Thermal performance of buildings - Calculation of internal temperatures of a room in summer without mechanical cooling - General criteria and validation procedures ([EN] ISO 13791). Superseded by [EN] ISO 52016- and [EN] ISO 52017-1.

International Organization for Standardization (2012). Thermal performance of buildings - Calculation of internal temperatures of a room in summer without mechanical cooling - Simplified methods ([EN] ISO 13792). Superseded by [EN] ISO 52016- and [EN] ISO 52017-1.

International Organization for Standardization (2017). Energy performance of buildings - Overarching
EPB assessment - Part 1: General framework and procedures ([EN] ISO 52000-1).

International Organization for Standardization (2017). Energy performance of buildings - Indicators, requirements, ratings and certificates - Part 1: General aspects and application to the overall energy performance ([EN] ISO 52003-1).

International Organization for Standardization (2017). Energy performance of buildings - External climatic conditions - Part 1: Conversion of climatic data for energy calculations ([EN] ISO 52010-1).

International Organization for Standardization (2017). Energy performance of buildings - Energy needs for heating and cooling, internal temperatures and sensible and latent heat loads - Part 1: Calculation procedures ([EN] ISO 52016-1).

International Organization for Standardization (2017). Energy performance of buildings -- Sensible and latent heat loads and internal temperatures -- Part 1: Generic calculation procedures ([EN] ISO 52017-1).

International Organization for Standardization (2017), Energy performance of buildings - Energy needs for heating and cooling, internal temperatures and sensible and latent heat loads - Part 2: Explanation and justification of ISO 520161 and ISO 52017 I ([CEN] ISO/TR 52016 2).

International Organization for Standardization (2017). Energy performance of buildings - Indicators for partial EPB requirements related to thermal energy balance and fabric features - Part 1: Overview of options ([EN] ISO 52018-1).

International Organization for Standardization (2017), Energy performance of buildings - Hygrothermal performance of building components and building elements - Part 2: Explanation and justification ([CEN] ISO/TR 520192).

Loonen, Roel C.G.M., Fabio Favoino, Jan L.M. Hensen \& Mauro Overend, (2017), Review of current status, requirements and opportunities for building performance simulation of adaptive facades, Journal of Building Performance Simulation, 10 (2), 205223.

Mandate M/480 (2010), Mandate to CEN, CENELEC and ETSI for the elaboration and adoption of standards for a methodology calculating the integrated EPB and promoting the EE of buildings, in acc. with the terms set in the recast EPBD (2010/31/EU), December 14, 2010.

Plokker, W. and D. van Dijk (2016), EPB standard EN ISO 52010: Conversion of climatic data for energy calculations: completion of a missing link, REHVA Journal, 53 (3), 12 - 16.

Poel, B. (2007), Contribution to "Applying the EPBD to improve the Energy Performance Requirements to Existing Buildings" Final Report of WP1 of ENPEREXIST, 10 - 15 . 